\title{
Treatment outcome following use of the erbium, chromium:yttrium, scandium, gallium, garnet laser in the non-surgical management of peri-implantitis: a case series
}

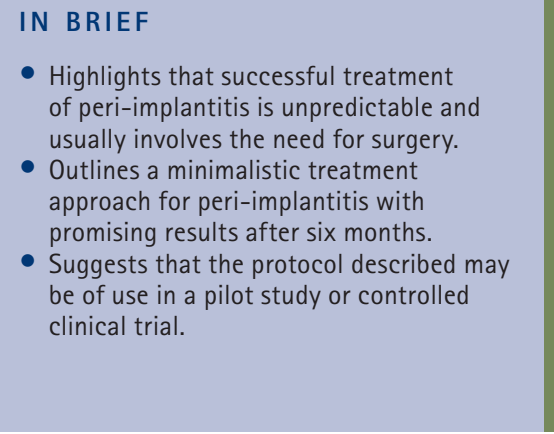

\author{
R. Al-Falaki, ${ }^{* 1}$ M. Cronshaw ${ }^{2}$ and F. J. Hughes ${ }^{3}$
}

\section{VERIFIABLE CPD PAPER}

\begin{abstract}
Aim To date there is no consensus on the appropriate usage of lasers in the management of peri-implantitis. Our aim was to conduct a retrospective clinical analysis of a case series of implants treated using an erbium, chromium:yttrium, scandium, gallium, garnet laser. Materials and methods Twenty-eight implants with peri-implantitis in 11 patients were treated with an

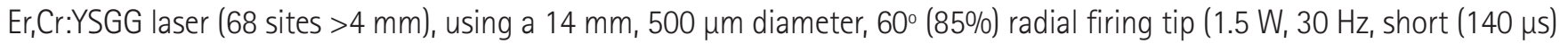
pulse, $50 \mathrm{~mJ} /$ pulse, 50\% water, 40\% air). Probing depths were recorded at baseline after 2 months and 6 months, along with the presence of bleeding on probing. Results The age range was 27-69 years (mean 55.9); mean pocket depth at baseline was $6.64 \pm$ SD $1.48 \mathrm{~mm}$ (range 5-12 mm), with a mean residual depth of $3.29 \pm 1.02 \mathrm{~mm}$ (range 1-6 mm) after 2 months, and $2.97 \pm 0.7 \mathrm{~mm}$ (range 1-9 $\mathrm{mm}$ ) at 6 months. Reductions from baseline to both 2 and 6 months were highly statistically significant $(\mathrm{P}<0.001)$. Patient level reduction in bleeding from baseline to both 2 and 6 months were statistically significant $(P<0.001)$. Conclusion In view of the positive findings in this pilot study, well-designed randomised controlled trials of the use of Er,Cr:YSGG laser in the non-surgical management of peri-implantitis are required to validate our clinical findings.
\end{abstract}

\section{INTRODUCTION}

Peri-implant mucositis and peri-implantitis are destructive inflammatory conditions that are mainly initiated by bacterial insult. ${ }^{1}$ Pathogens form as a biofilm that activates inflammatory cells which then release cytokines and enzymes that are harmful to the surrounding tissues. ${ }^{2}$ The role of plaque in the disease process is well documented. ${ }^{3-7}$

A number of studies have reported that the optimum outcome in the reduction of probing depth (PD), clinical attachment level (CAL) and bone levels in association with peri-implant osseous defects was achieved by surgery in conjunction with augmentative products including natural bone material and barrier membranes. ${ }^{8,9}$ However, an ideal method to decontaminate the infected implant surface has not been determined. ${ }^{10-12}$

'Specialist In Periodontics, Private Practice, Al-FaPerio Clinic, 48A Queens Road, Buckhurst Hill, Essex, IG9 5BY; ${ }^{2}$ Private Practice, Amery House, 4 Terminus Road, Cowes, P031 7TG; ${ }^{3}$ Dept of Periodontology, Kings College London Dental Institute, Floor 21, Tower Wing Guys Hospital, London, SE1 9RT

${ }^{*}$ Correspondence to: Rana Al-Falaki

Email: info@al-faperio.co.uk

\section{Refereed Paper}

Accepted 11 August 2014

DOI: 10.1038/sj.bdj.2014.910

${ }^{\circ}$ British Dental Journal 2014; 217: 453-457
A variety of methods of implant decontamination have been proposed. There are many published studies showing the effective mechanical and bacterial debridement by laser application of contaminated titanium implant surfaces in in vitro studies. ${ }^{12-14}$ Laser applications to debride contaminated implant surfaces in the erbium wavelengths of 2,940 $\mathrm{nm}$ and 2,780 $\mathrm{nm}$ have been subject to animal and a limited number of clinical studies. ${ }^{15-20}$ Erbium laser energy of these wavelengths is capable of ablating and vaporising residual organic debris, including microbial plaque, and has been found to be able to disinfect and remove the peri-implant pocket's sulcular lining. ${ }^{21}$

To date, however, there is no consensus on the appropriate use of lasers in the management of peri-implantitis. A recent systematic review and meta-analysis of the ErYAG 2,940 $\mathrm{nm}$ laser concluded that the current evidence base supported the use of the ErYAG laser to reduce inflammation although there was no evidence to support a significant reduction in CAL or PD. ${ }^{22}$ There are at present only a few clinical studies reporting on the efficacy of the 2,780 $\mathrm{nm}$ ErCrYSGG laser in the management of peri-implantitis. ${ }^{23-25}$

Surgical intervention to treat infrabony defects around implants may involve the use of regenerative materials and barrier membranes. ${ }^{26}$ The difficulty of adequately debriding the contaminated implant surface, as well as the removal of associated granulation tissue, poses a serious problem which can result in treatment failure. ${ }^{27,28}$ Recent reviews and metaanalyses of the evidence base on the adjunctive use of lasers in the non-surgical management of peri-implantitis have failed to show an advantage over other non-surgical approaches, and none over surgical approaches. Also the current consensus view is that the non-surgical management of peri-implantitis associated with and without infrabony defects is an unpredictable treatment modality. ${ }^{8-10,22,29}$

There are relatively few reports in the literature of the application of the ErCr:YSGG laser in the non-surgical and surgical management of periodontitis. ${ }^{29-33}$ However, the studies on record to date demonstrate that pocket depths around infected teeth typically halve after a single application of the 2,780 nm laser in a non-surgical protocol. $^{30-32}$ This technique involves the removal of granulation tissue from the lining of the infected pocket, root surface debridement and de-epithelialisation, all achieved by the application of $500 \mu \mathrm{m}$ diameter $60^{\circ}$ zirconium radial firing periodontal tips (Biolase Technology, Inc., San Clemente, CA). 


\begin{tabular}{|c|c|c|c|c|}
\hline $\begin{array}{l}\text { Patient } \\
\text { no. }\end{array}$ & Gender & Smoker & Age & $\begin{array}{l}\text { Implant } \\
\text { no. }\end{array}$ \\
\hline \multirow[t]{4}{*}{1} & Male & No & 62 & 1 \\
\hline & & & & 2 \\
\hline & & & & 3 \\
\hline & & & & 4 \\
\hline \multirow[t]{6}{*}{2} & Female & Yes & 57 & 5 \\
\hline & & & & 6 \\
\hline & & & & 7 \\
\hline & & & & 8 \\
\hline & & & & 9 \\
\hline & & & & 10 \\
\hline 3 & Female & No & 45 & 11 \\
\hline 4 & Female & No & 59 & 12 \\
\hline \multirow[t]{3}{*}{5} & Male & No & 64 & 13 \\
\hline & & & & 14 \\
\hline & & & & 15 \\
\hline \multirow[t]{3}{*}{6} & Male & Yes & 51 & 16 \\
\hline & & & & 17 \\
\hline & & & & 18 \\
\hline \multirow[t]{2}{*}{7} & Male & No & 27 & 19 \\
\hline & & & & 20 \\
\hline \multirow[t]{2}{*}{8} & Male & No & 60 & 21 \\
\hline & & & & 22 \\
\hline 9 & Male & No & 69 & 23 \\
\hline 10 & Female & No & 53 & 24 \\
\hline \multirow[t]{4}{*}{11} & Male & No & 68 & 25 \\
\hline & & & & 26 \\
\hline & & & & 27 \\
\hline & & & & 28 \\
\hline
\end{tabular}

In view of the reports of successful treatment of periodontal disease with Er,Cr:YSGG lasers $^{30-32}$ and the author's empirically observed successes of this treatment in a periodontal practice setting it was decided to apply the same principles in an attempt to non-surgically treat peri-implantitis.

This study reports on a clinical case series followed over 6 months and is a retrospective analysis of the use of the 2,780 $\mathrm{nm}$ Er,CrYSGG laser in the management of peri-implantitis using a minimally invasive approach.

\section{MATERIALS AND METHODS}

Patients with a clinical diagnosis of periimplantitis at consultation, based on the clinical and radiographic findings, were eligible for inclusion in this analysis. Implants with at least one site $>4 \mathrm{~mm}$ and evidence of bone loss compared to baseline radiographs, were included. No exclusions were made based on smoking or medical history.

Two percent lignocaine hydrochloride

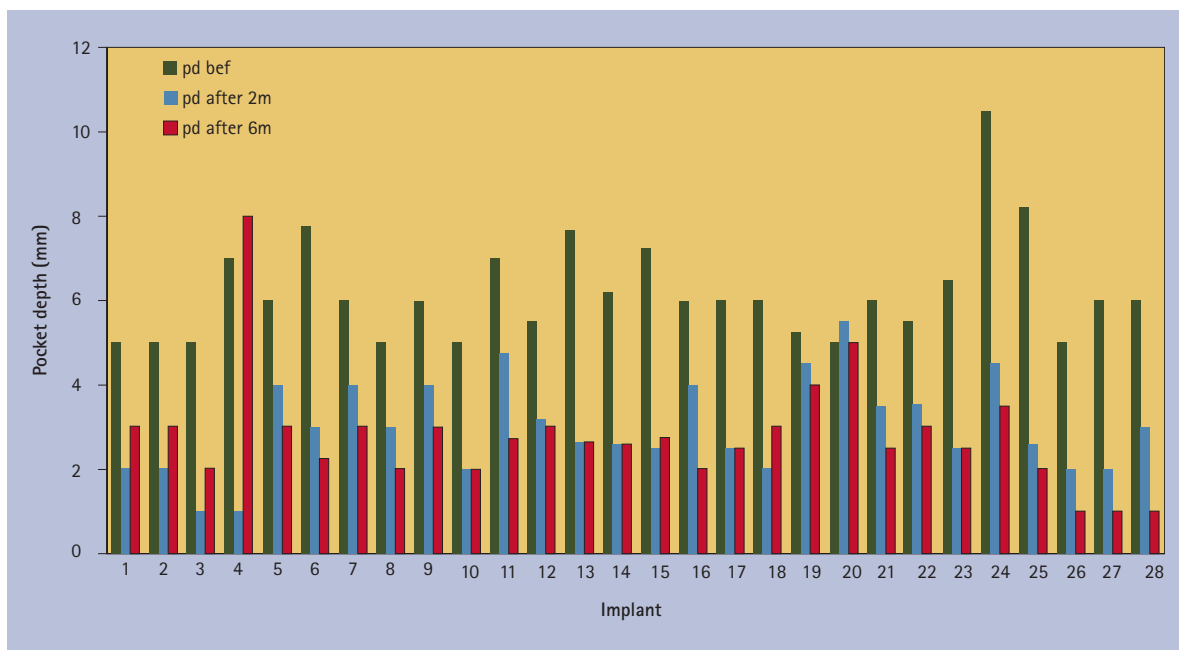

Fig. 1 Mean pocket depth of affected implants before treatment (pd bef), 2 and 6 months after treatment (PD after 2, PD after 6)

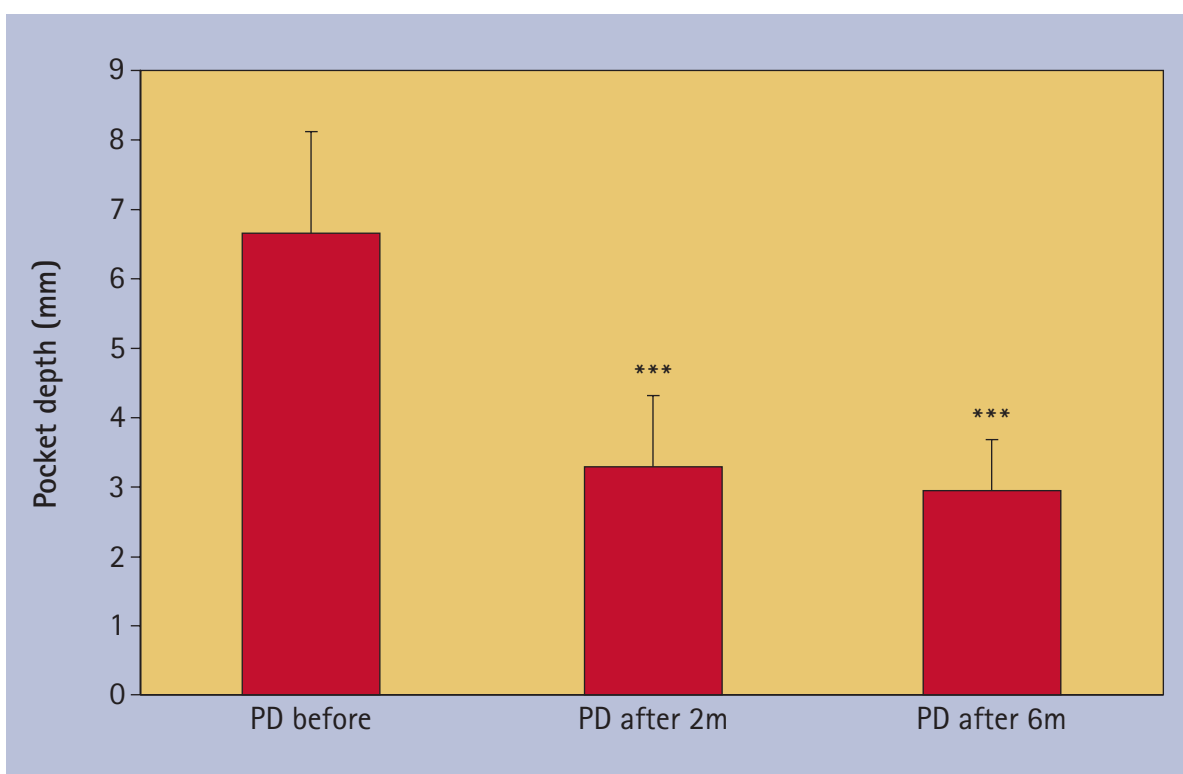

Fig. 2 Mean pocket depth of implants from each patient before treatment (pd bef), 2 and 6 months after treatment (PD after 2 months, PD after 6 months) $(N=11)$. ${ }^{* * P}<<0.001$ significantly different from baseline by repeated measures ANOVA and Bonferroni post test

solution with 1:80,000 adrenaline local anaesthetic was administered at all sites affected by pocketing as a combination of buccal and lingual infiltrations to achieve bone and soft tissue anaesthesia. The pockets were treated with the Er,Cr:YSGG laser using a $14 \mathrm{~mm}, 500 \mu \mathrm{m}$ radial firing periodontal tip (Biolase, Irvine California, RFPT5). The settings used were: power $1.5 \mathrm{~W}$, frequency $30 \mathrm{~Hz}, 50 \%$ water, 40\% air, $50 \mathrm{~mJ} /$ pulse, $140 \mu$ s pulse duration. The same settings were used in each case. The tip was inserted into the base of the pocket and maintained at an angle parallel to the long axis of the implant and the epithelial lining as much as possible. Once it touched bone, it was withdrawn slightly, and constantly moved vertically (apico-coronal), up and down the pocket and side to side (either bucco-lingual or mesio-distal depending on location of the pocket) with slow smooth sweeping motions.
This was continued until no further deposits of granulation tissue were seen to be coming out of the pocket (typically taking up to around 15 minutes/implant if widespread circumferential pocketing). A titanium curette was then used to scrape along the pocket epithelium and bony walls to ensure that all granulation tissue had indeed been removed. The laser tip was then re-inserted and moved slowly, and angled this time furstly parallel to the implant surface, and then towards all the bony walls surrounding the implant, now that the granulation tissue had been removed. This was a much briefer laser application, just ensuring energy contact with all the surface area of bone and exposed implant. Finally the tip was run outside the pocket, parallel to the tissue, to disrupt the epithelium surrounding the implant by a distance of at least $5 \mathrm{~mm}$ from the gingival margin. 


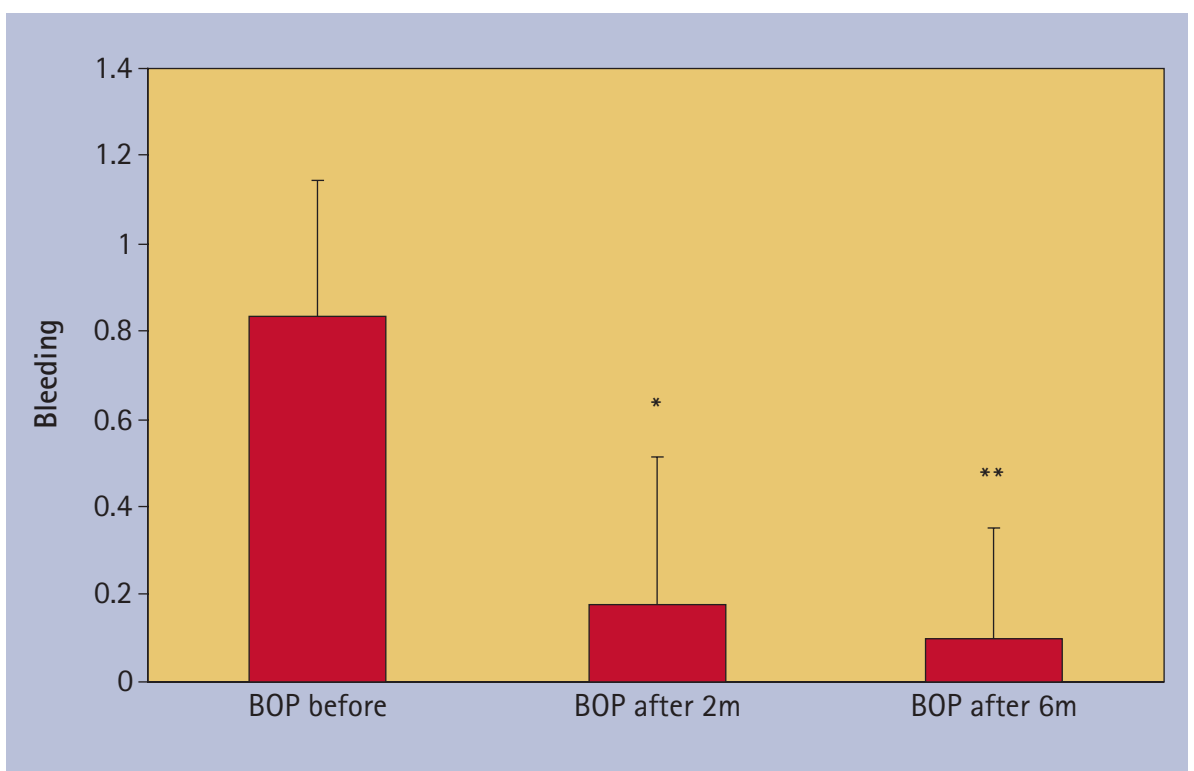

Fig. 3 Mean bleeding score of implants from each patient before treatment (pd bef), 2 and 6 months after treatment (PD after 2 months, PD after 6 months) $(N=11) .{ }^{*} P<0.05,{ }^{* *} P<0.01$ significantly different form baseline by Friedman's test and Dunn's post test
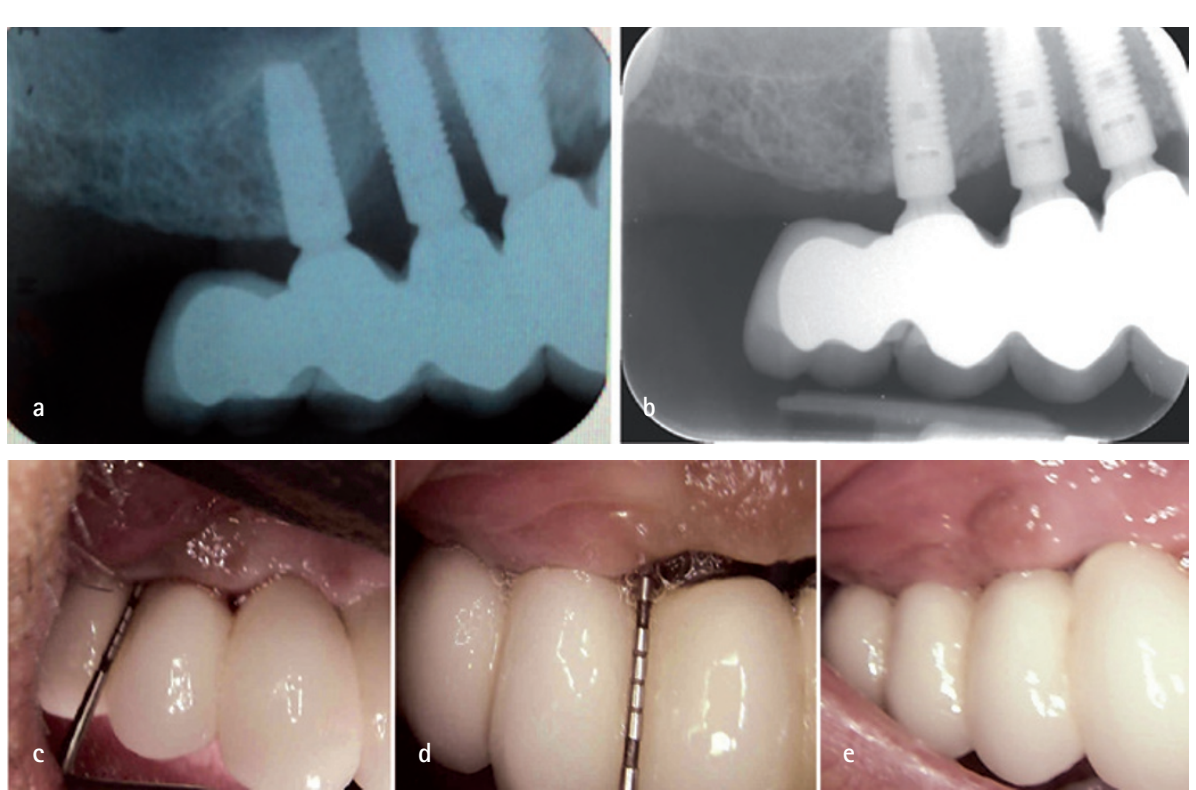

Fig. 4 Case 1: Radiographs taken before (a) and after 14 months (b). Some suggestion of bone fill of 2 thread on distal, and 4 threads on mesial aspect of 14 implant. (c) Photograph showing $8 \mathrm{~mm}$ pocket on distal of 14 implant before treatment, and (d) $3 \mathrm{~mm}$ pd 2 months later, along with recession. (e) Creep back of tissues 14 months later, with less recession in region of 14

If bleeding was excessive following the procedure, pressure with water-moistened damp gauze was applied to the tissues until bleeding stopped. Patients were advised to commence brushing as normal the next day and to use appropriate sized interdental, wire-free brushes. All treatment was carried out with the fixtures in place, with no occlusal adjustment, and no adjunctive antimicrobials were used.

Periodontal reassessment was carried out at 2 months consisting of probing depths and bleeding on probing, and repeated again at 6 months. Follow-up radiographs (periapicals with paralleling technique) were taken at that stage or at later reviews over-irradiating the patient as this was not conducted as a clinical trial. Observations noted over time led to this more in-depth analysis. Post-operative radiographs were not taken until at least 7 months post treatment, and only if the results demonstrated pocket resolution that had remained stable to date.

\section{Data analysis}

The mean of pocket depths and bleeding score around each implant were calculated. Statistical analysis was carried out at a patient level $(\mathrm{N}=11)$ by taking the mean pocket depth and bleeding score around each implant and used to calculate a mean for each patient. Differences between baseline were determined 2 months post-operatively and 6 months post-operatively using repeated measures ANOVA and Bonferroni post test for pocket depths and Friedman's test and Dunn's multiple comparisons test for bleeding scores. Statistical analyses were carried out using GraphPad Prism software.

\section{RESULTS}

The age range of patients was 27 to 69 years old, with a mean of 55.9 years. Two patients were smokers, and no patients had a medical history that would typically compromise the results, such as uncontrolled diabetes or being immuno-compromised. Treatment was mostly uneventful, with no reported pain or discomfort post-operatively. The basic demographics and distribution of implants treated are shown in Table 1 .

Mean pocket depth reductions for all implants are shown in Figure 1. There was a marked reduction in pocket depths seen with almost all sites treated. One implant (Implant 4) showed a marked reduction at 2 months but complete relapse by 6 months; only 2 other implants (19 and 20) showed no significant reduction following treatment. Analysis of responses by patients showed baseline pocket depth measurements ranging from 5 to $12 \mathrm{~mm}$ with a mean \pm SD of $6.64 \pm 1.48 \mathrm{~mm}$, with a mean residual depth of $3.29 \pm 1.02 \mathrm{~mm}$ after 2 months, and $2.97 \pm 0.7 \mathrm{~mm}$ at 6 months. Reductions from baseline to both 2 and 6 months were highly statistically significant $(\mathrm{P}<0.001$ by repeated measure ANOVA and bonferroni post test) (Fig. 2). Eighty-eight percent of sites were bleeding at baseline, $18 \%$ after 2 months, and 10\% after 6 months. Patient level reduction in bleeding from baseline to both 2 and 6 months were statistically significant $(\mathrm{P}<0.001$ by Friedman's test and Dunn's post test) (Fig. 3).

Recession occurred following treatment, with the exposure of implant surface and threads in many cases, as illustrated in case 
3. The threads were not smoothed down, but it was ensured that the patient was able to clean the implant surface effectively. Over time, in many cases, the recession reduced, with less exposure of threads, and radiographically, some bone fill was observed when initially associated with vertical defects around the implants, but this was quite subjective.

\section{DISCUSSION}

The results of this study demonstrate that treatment resulted in the resolution $(<4 \mathrm{~mm})$ of $91 \%$ of sites, and unresponsive outcomes in only 3 of 28 implants, none of the latter having keratinised tissue around them, which may have been a factor in affecting plaque control in these cases. In addition, by 6 months, 10\% of total pockets were bleeding on probing. The use of Er,Cr:YSGG laser as a non-surgical aid to the management of peri-implantitis seems to be effective in the majority of cases in this analysis, allowing for the limitations within the study.

It is also of interest that sequential nonstandardised radiographs suggest some infill of bone with fewer threads exposed (cases 1 , 2 and 3; Figs 4-6), although this was quite minor and therefore possibly worthy of further study or follow-up over a longer period of time. In addition over a period of observation of fourteen months, author R. Al-F has observed a degree of creeping reattachment (case 1), with less recession and implant exposure over time.

A number of recent systematic reviews have addressed the issue of whether or not lasers may be useful in the management of peri-implantitis..$^{22,32-34} \mathrm{~A}$ very recent review by Kotsakis et al. ${ }^{22}$ concluded that nonsurgical laser therapy may be investigated as phase I (non-surgical) therapy for the treatment of peri-implantitis, with a view to perhaps needing surgery as a second phase treatment after 6 months. However, they also pointed out the limitations of the systematic review and meta-analysis due to the high heterogeneity and the low number of included studies. Unlike the results found in the present analysis, they demonstrated that most lasers seemed to be beneficial in the reduction of inflammation, but did not significantly reduce probing depths. Another limitation was the lack of information in studies about power settings, tips used, angulations and doses. This means that it is difficult to be able to compare success rates satisfactorily.

To date published research on lasers and peri-implantitis have largely focused on the 2,940 nm Er:YAG and the 9,600/10,600 nm $\mathrm{CO}_{2}$ lasers..$^{23,33-35}$ The choice of these particular wavelengths is based on the findings that
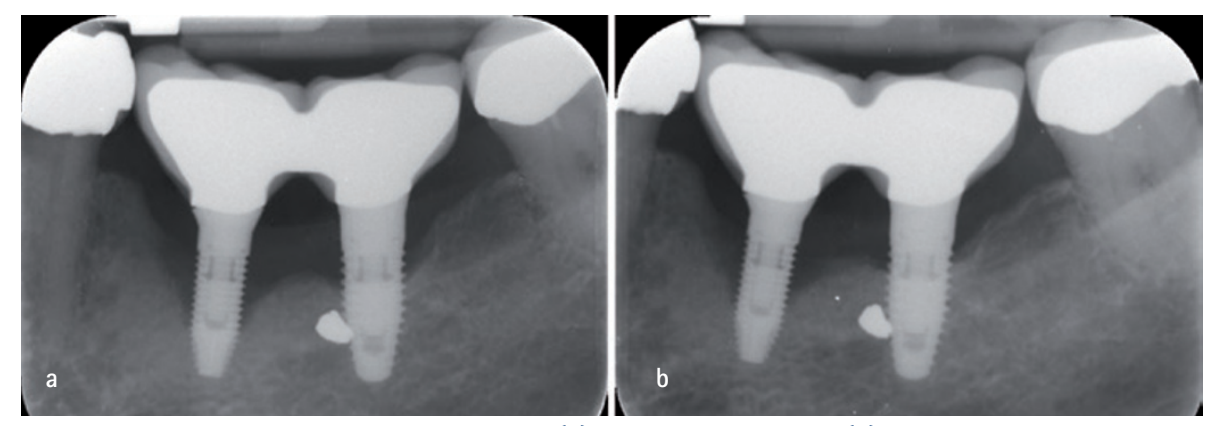

Fig. 5 Case 2: Radiographs showing before (a) and after 7 months (b) - bone level down to 4th thread before and 2 nd thread 7 months later on distal aspect of 35 implant, and mesially some bone fill from 4 th to 2 nd thread. Very little change visible on 34 implant
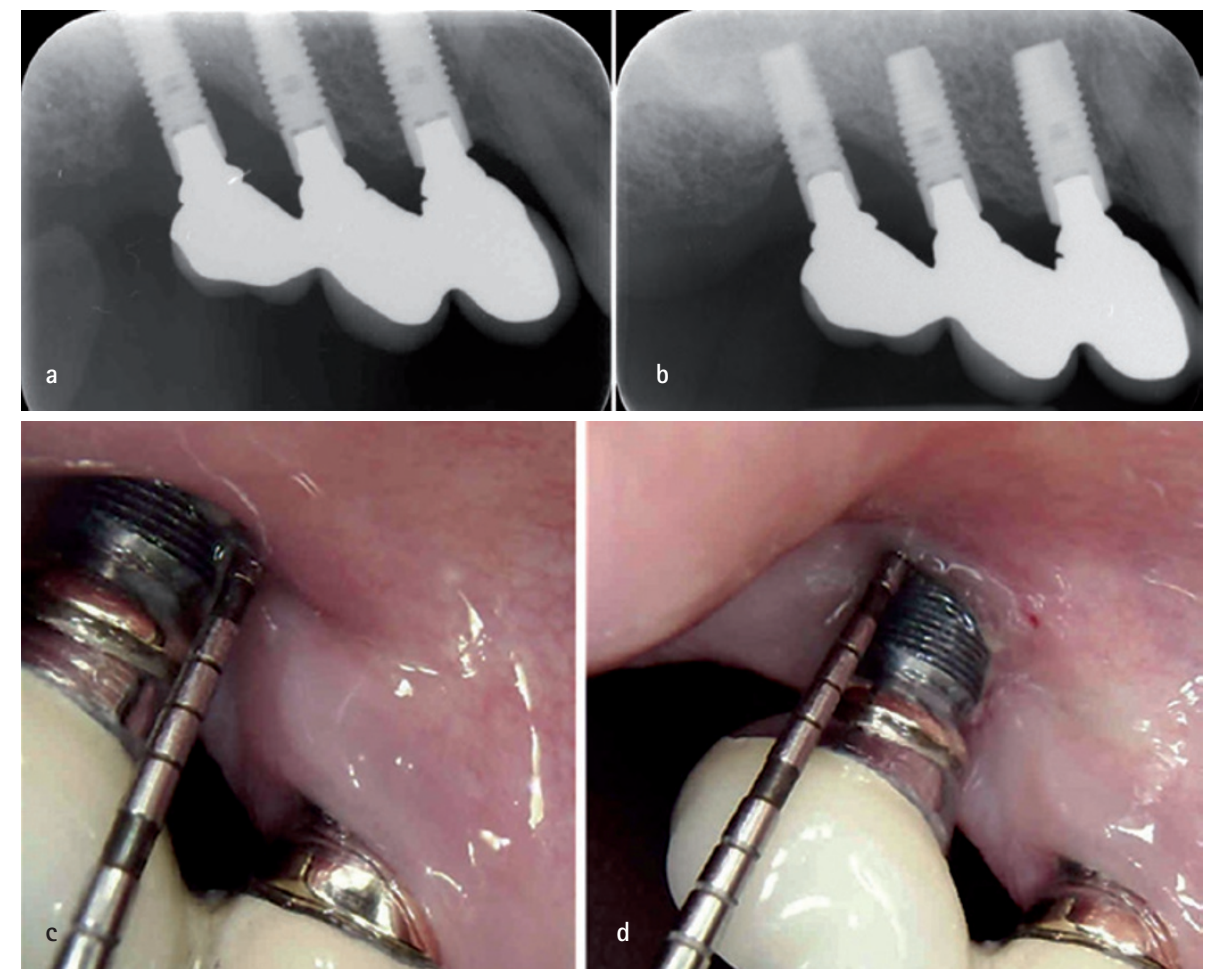

Fig. 6 Case 3: Radiographs showing before (a) and after 7 months (b). Some bone visible distally form 6th thread pre-treatment, to 3rd thread after treatment. Photograph showing $3 \mathrm{~mm}$ probing depths mesially (c) and distally (d) 2 months after treatment, with considerable exposure of threads and recession. Pockets had reduced from $10 \mathrm{~mm}$ distally and $9 \mathrm{~mm}$ mesially

these are safe wavelengths to use which can remove biofilm and infected tissue without collateral adverse thermal or structural damage. $^{35-37}$ The 2,780 nm Er,Cr:YSGG laser is a very similar wavelength to the $2,940 \mathrm{~nm}$ Er:YAG laser and the primary chromophore of both of these lasers is water. On exposure to laser energy at this wavelength water expands explosively by a factor of $1600 x$ in $1 / 50$ th of a second and this rapid expansion produces beneficial clinical effects by virtue of the effective disruption of biofilm, the destruction of bacteria and the ability to debride infected surfaces of smear layer. In addition it is possible to remove infected tissues without untoward damage to superficial tissues as well as remove calculus. ${ }^{38-44}$

The protocol adopted in this case series involved the application of radial firing tips (RFT) (Biolase Technology, Inc., San
Clemente, CA). The relatively novel use of RFTs in the treatment of peri-implantitis has not thus far been described in the literature. In all of the implant-related clinical studies on the Er:YAG laser, the energy has been delivered to the target tissues using end firing tips. Previous studies utilising end firing tips and the 2,940 $\mathrm{nm}$ Er:YAG laser in controlled studies have found that there was little difference between laser and control protocols in outcome when applied non surgically and the outcome of a reduction of pocket depth post therapy was of the order of 0.8-0.9 mm..$^{22,32-34}$ By contrast in this study the order of event was of a different magnitude and pocket depths reduced on average by $3.5 \mathrm{~mm}$. In similarity to other laser studies, the reduction in bleeding on probing and inflammation was highly significant. This may be a consequence of the markedly 
different energy distribution by the RFT's enhancing the effective removal of biofilm as well as aiding access without raising a surgical flap to areas otherwise difficult to reach with conventional end firing tips.

At this stage this study comprises a retrospective analysis of a case series and as such represents a low level of evidence for the efficacy of the laser. The results, however, are impressive and are sufficiently supported by the statistical analysis to be hypothesis forming. In view of the excellent results gained in this pilot study, it is proposed that well-designed randomised controlled trials of the use of Er,Cr:YSGG laser in the non surgical management of peri-implantitis are required to validate our clinical findings.

Conflict of interest statment

Author $R$ AlF has been the recipient of lecture fees from Biolase Inc. Author FJH's hospital department has received some free materials and discounted equipment from Biolase Inc. and Henry Schein Ltd. Author MC has received lecture fees, free materials and discounted equipment from Biolase Inc. and Henry Schein Ltd.

1. Rosen P, Clem D, Cochran D. Peri-mucositis and peri-implantitis: a current understanding of their diagnoses and clinical implications. J Periodontol 2013; 84: 430-443.

2. Lindhe J, Meyle J. Peri-implant diseases: Consensus report of the Sixth European Workshop on Periodontology. J Clin Periodontol 2008; 35(Suppl. 8): 282-285.

3. Silverstein L H, Kurtzman D, Garnick J J. The microbiota of the peri-implant region in health and disease. Implant Dent 1994; 3: 170-174.

4. Becker W, Becker B E, Newman M G, Nyman S. Clinical and microbiologic findings that may contribute to dental implant failure. Int J Oral Maxillofac Implants 1990; 5: 31-38.

5. Berglundh T, Lindhe J, Marinello C, Ericsson I, Liljenberg B. Soft tissue reaction to de novo plaque formation on implants and teeth. An experimental study in the dog. Clin Oral Implants Res 1992; 3: 1-8.

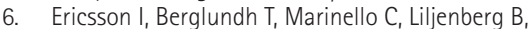
Lindhe J. Long-standing plaque and gingivitis at implants and teeth in the dog. Clin Oral Implants Res 1992; 3: 99-103.

7. Mombelli A, Lang N P. Antimicrobial treatment of peri-implant infections. Clin Oral Implants Res 1992; 3: 162-168.

8. Esposito M, Grusovin M G, Kakisis I, Coulthard P Worthington H V. Interventions for replacing missing teeth: treatment of perimplantitis. Cochrane Database Syst Rev 2008; CD004970.

9. Renvert S, Polyzois I, Persson G R Treatment modalities for peri-implant mucositis and periimplantitis. Am J Dent 2013; 26: 313-318.

10. Kotsovilis S, Karoussis I K, Trianti M, Fourmousis I. Therapy of peri-implantitis: a systematic review.
J Clin Periodontol 2008: 35: 621-629.

11. Ntrouka VI, Slot D E, Louropoulou A, Van der Weijden $F$. The effect of chemotherapeutic agents on contaminated titanium surfaces: a systematic review. Clin Oral Implants Res 2011; 22: 681-689.

12. Kreisler M, Kohnen W, Marinello C et al. Bactericidal effect of the Er: YAG laser on dental implant surfaces: an in vitro study. J Periodontol 2002; 73: 1292-1298.

13. Kreisler M I, Kohnen W, Christoffers A B et al. In vitro evaluation of the biocompatibility of contaminated implant surfaces treated with an Er:YAG laser and an air powder system. Clin Oral Implants Res. 2005; 16: $36-43$.

14. Schwarz F, Nuesry E, Bieling K. Influence of an erbium chromium yttrium garnet (Er, Cr: YSGG) laser on the reestablishment of the biocompatibility of contaminated titanium implant surfaces. J Periodonta/ 2006; 77: 1820-1827.

15. Schwarz F, Jepsen $S$, Herten M, Sager M, Rothamel $D, B e c k e r$ J. Influence of different treatment approaches on unsubmerged and submerged healing of ligature induced peri-implant lesions. An experimental study in dogs. J Clin Periodontol 2006 33: 584-595.

16. Schwarz F, Bieling K, Nuesry E, Sculean A, Becker $J$. Clinical and histological healing pattern of periimplantitis lesions following non-surgical treatment with an Er: YAG laser. Lasers Surg Med 2006; 38: 663-671.

17. Giannelli M, Pini A, Formigli L, Bani D. Comparative in vitro study among the effects of different laser and LED irradiation protocols and conventional chlorhexidine treatment for deactivation of bacterial lipopolysaccharide adherent to titanium surface. Photomed Laser Surg. 2011; 29: 573-580.

18. Persson G, Roos-Jansaker A, Lindahl C, Renvert S. Microbiological results after non surgical erbium doped yttrium, aluminium, and garnet laser or airabrasive treatment of peri-implantitis: a randomized clinical trial. J Periodonto/ 2011; 82: 1267-1278.

19. Schwarz F, Sahm N, Iglhaut G. Impact of the method of surface debridement and decontamination on the clinical outcome following combined surgical therapy of peri-implantitis: a randomized controlled clinical study. J Clin Periodontol 2011; 38: 276-284.

20. Schwarz F, Hegewald A, John G, N, Becker J. Fouryear follow-up of combined surgical therapy of advanced peri-implantitis evaluating two methods of surface decontamination. J Clin Periodontol 2013; 40: 962-967.

21. Takasaki A A, Aoki A, Mizutani K, Kikuchi S, Oda S, Ishikawa I. Er: YAG laser therapy for peri-implant infection: A histological study. Lasers Med Sci 2007; 22: 143-157.

22. Kotsakis G, Konstantinidis I, Karoussis I. A systematic review and meta-analysis of the effect of various laser wavelengths in the treatment of peri-implantitis. J Periodontol. 2014; 85: 1203-1213.

23. Miller R. Treatment of the contaminated implant surface using the $\mathrm{Er}, \mathrm{Cr}$ : YSGG laser. Implant Dentistry 2004; 13: 165-169.

24. Azzeh M. Er, Cr: YSGG laser assisted surgical treatment of peri-implantitis with 1 year re-entry and 18 month follow up. J Periodontol 2008; 79: 2000-2005.

25. Smith $L P$, Rose $T$. Laser explantation of a failing endosseous dental implant Aus Dent J 2010; 55:
219-222.

26. Wang $H \mathrm{~L}$, Greenwell $H$, Florellini J. Periodontal regeneration. J Periodontol. 2005; 76: 1601-1622.

27. Leonhardt A, Renvert S, Dahlén G. Microbial findings at failing implants. Clin Oral Implants Res 1999; 10: 339-345.

28. Shibli J A, Melo L, Ferrari D S, Figueiredo L C, Faveri M, Feres M. Composition of supraand subgingival biofilm of subjects with healthy and diseased implants. Clin Oral Implants Res 2008; 19: 975-982.

29. Mailoa J I, Lin G H, Chan H L, Maceachern M, Wang H L. Clinical outcomes of using lasers for peri-implantitis surface detoxification: a systematic review and meta-analysis. J Periodontol. 2014; 85: 1194-1202.

30. Kelbauskiene S, Baseviciene N, Goharkhay K, Moritz A \& Machiulskiene V. One-year clinical results of Er, Cr: YSGG laser application in addition to scaling and root planing in patients with early to moderate periodontitis. Lasers Med Sci 2011: 26, 445-452.

31. Dyer B, Sung E C. Minimally invasive periodontal treatment using the Er, Cr: YSGG laser. A 2year retrospective preliminary clinical study. Open Dent $J$ 2012; 6: 74-78.

32. Dederich D. Periodontal bone regeneration and the Er, Cr: YSGG: a case report. Open Dent J 2013; 7: 16-19.

33. Deppe H\&t Henning Horch $\mathrm{H}$. Laser applications in oral surgery and implant dentistry. Lasers Med Sci 2007; 22: 217-221.

34. Meyle J. Mechanical, chemical and laser treatments of the implant surface in the presence of marginal bone loss around implants. Eur J Oral Implantol. 2012; 5: S71-81.

35. Riziou M, Evensole R, Kimmel A. Effects of Er, Cr: YSGG lasers on mucocutaneous soft tissues. Oral Surg Oral Med Oral Path Radiol Endod. 1996; 82: 386-395.

36. Zaffe D, Viatle M, Martignone A. Morphological histochemical and immunocytochemical study of $\mathrm{CO}_{2}$ and $\mathrm{Er}$ : YAG laser effects on oral soft tissues. Photomed Laser Surg 2004; 22: 185-189.

37. Parker $\mathrm{S}$, Laser: tissue interaction and its application in clinical dentistry. Int J Laser Dent 2011; 1: 1-8.

38. Ando Y, Aoki A Watanabe H. Bactericidal effects of erbium YAG on periodontopathic bacteria. Lasers Surg Med 1996; 19: 190-200.

39. Schoop U, Kluger W, Moritz A Nedjelik N. Bactericidal effect of different laser systems in the deep layers of dentin. Lasers Surg Med 2004; 35: 111-116.

40. Eberhard J, Ehlers H, Falk W, Acil Y, Albers H K, Jepsen S. Efficacy of subgingival calculus removal with Er YAG laser compared to mechanical debridement an in situ study. J Clin Periodontol. 2003; 30: 511-518.

41. Folwaczny $M$, Aggstaller $H$, Mehi $A$, Hickel $R$. Removal of bacterial endotoxin from root surface with Er: YAG laser. Am J Dent. 2003; 16: 3-5.

42. Aoki $A$, Sasaki $K$, Watanabe $H$. Lasers in nonsurgical periodontal therapy. Periodontol 2000; 2004: 36: 59-97.

43. Cobb C M. Lasers in periodontics a review of the literature. J Periodonto/ 2006; 77: 545-564.

44. Krause F, Braun A, Brede O, Eberhard J, Frentzen M, Jepsen $\mathrm{S}$. Evaluation of selective calculus removal by a fluorescence feedback-controlled Er YAG laser in vitro. J Clin Periodontol 2007; 34: 66-71. 